\title{
FAKTOR YANG MEMENGARUHI TERJADINYA KECELAKAAN KERJA PADA KARYAWAN DI PT. ANDALAN FLUID SISTEM KABUPATEN MAROS
}

Factors that Affect the Occurrence of Work Accidents on Employees at PT. Andalan

Fluid System Maros Regency

Reskita Nova Maharani ${ }^{1}$, Hamsir $^{2}$

1,2,3 Jurusan Kesehatan Lingkungan Poltekkes Kemenkes Makassar

Email: reskitanm@gmail.com

\begin{abstract}
Occupational Safety and Health (OSH) is a field related to health, safety and welfare of people who work in an industry or project location. K3 also protects coworkers, workers' families, consumers, and other people who may also be affected by the condition of working environment. This study aims to find out what factors influence the occurrence of work accidents at PT. Andalan Fluid System, Maros. The type of research used in this study was analytic observational research with cross sectional design. The results show that there are 31 out of 65 respondents who worked (> 3 years), never experienced work accidents 24 (77.4\%) and 7 (22.6\%) had experienced work accidents. For work period ( $\leq 3$ years) there are 25 (73.5\%) who have never had work accident and 9 (26.5\%) have had work accident. Users of complete PPE with a total of 40 (85.1\%), there are 7 who experienced an accident of work (14.9\%), there are 9 who did not use complete PPE (50.0\%), 9 experiencing work accident (50.0\%). There are 46 behavior that gives positive responses, 39 who have never experienced work accidents (84.8\%) and $7(15.2 \%)$ have experienced work accidents. Those who gave a negative response are 10 (52.6\%) who had never had a work accident and 9 (47.4\%) had experienced work accidents. Then the temperature in the work area that has been measured from five points has an average temperature of $31.32{ }^{\circ} \mathrm{C}$. Based on the results of the research it can be concluded that there is an influence between the use of PPE, Behavior, and Air Temperature with the incidence of cruel accidents, whereas there is no influence between the period of work and the incidence of workplace accidents
\end{abstract}

Keywords : Work Accidents, Working Period, the Using of PPE, Behavior, Air Temperature

ABSTRAK

Keselamatan dan Kesehatan Kerja (K3) adalah bidang yang terkait dengan kesehatan, keselamatan, dan kesejahteraan manusia yang bekerja di sebuah industri maupun lokasi proyek. K3 juga melindungi rekan kerja, keluarga pekerja, konsumen, dan orang lain yang juga mungkin terpengaruh kondisi lingkungan kerja. Penelitian ini bertujuan mengetahui faktor apa saja yang memengaruhi terjadinya kecelakaan kerja di PT. Andalan Fluid Sistem Kabupaten Maros. Jenis penelitian yang digunakan pada penelitian ini yakni penelitian observasional analitik dengan rancangan cross sectional. Hasil penelitian menunjukkan bahwa dari 65 responden yang masa kerjanya (>3tahun) ada 31, tidak pernah mengalami kecelakaan kerja $24(77,4 \%)$ dan $7(22,6 \%)$ pernah mengalami kecelakaan kerja. Masa kerja ( $\leq 3$ tahun) ada 25 (73,5\%) tidak pernah mengalami kecelakaan kerja dan 9 (26,5\%) pernah mengalami kecelakaan kerja. Penggunaan APD dengan lengkap $40(85,1 \%)$, mengalami kecelakaan kerja $7(14,9 \%)$ yang tidak menggunakan APD dengan lengkap yaitu 9 (50,0\%) yang mengalami kecalakaan kerja $9(50,0 \%)$. Perilaku yang memberi respon positif ada 46 yang tidak pernah mengalami kecelakaan kerja $39(84,8 \%)$ dan $7(15,2 \%)$ pernah mengalami kecelakaan kerja. Yang memberi respon negatif 19 ada $10(52,6 \%)$ yang tidak pernah mengalami kecelakaan kerja dan $9(47,4 \%)$ yang pernah mengalami kecelakaan kerja. Serta suhu udara di area kerja yang telah diukur dari lima titik memiliki rata-rata suhu $31,32{ }^{\circ} \mathrm{C}$. Berdasarkan hasil penelitian dapat disimpulkan bahwa ada pengaruh antara penggunaan APD, Perilaku, dan Suhu Udara dengan kejadian kecelakaan kerja, sedangkan tidak ada pengaruh antara masa kerja dengan kejadian kecelakaan kerja.

Kata Kunci :Kecelakaan Kerja, Masa Kerja, Penggunaan APD, Perilaku, Suhu Udara

\section{PENDAHULUAN}

Keselamatan dan Kesehatan Kerja (K3) adalah bidang yang terkait dengan kesehatan, keselamatan, dan kesejahteraan manusia yang bekerja di sebuah industri maupun lokasi proyek. Tujuan K3 adalah untuk memelihara kesehatan dan keselamatan lingkungan kerja. K3 juga melindungi rekan kerja, keluarga pekerja, konsumen, dan orang lain yang juga mungkin terpengaruh kondisi lingkungan kerja.

Dalam era keterbukaan sekarang ini masalah perlindungan tenaga kerja akan menghadapi tantangan yang semakin berat berupa derasnya arus tuntutan tentang penerapan hak dasar pekerja di tempat kerja. Untuk itu pemerintah telah mengantisipasi hal tersebut dengan meratifikasi 15 Konvensi ILO, delapan diantaranya adalah konvensi yang berkaitan dengan hak-hak dasar. Perlindungan terhadap pekerja dilakukan dengan mengarahkan pada pemenuhan hak-hak dasar yang meliputi perlindungan upah, jaminan sosial tenaga kerja, waktu kerja dan waktu istirahat, perlindungan tenaga kerja wanita, anak dan orang muda, TKI yang bekerja di luar negeri dan terjaminnya keselamatan dan kesehatan kerja di tempat kerja.

Menurut (Suma'mur, 1996), banyak faktor yang berpengaruh dalam setiap kejadian kecelakaan kerja. Beberapa diantaranya yaitu faktor manusia, peralatan pendukung keselamatan dan sistem manajemen 
Jurnal Sulolipu : Media Komunikasi Sivitas Akademika dan Masyarakat

Vol. 19 No.2 2019

e-issn : 2622-6960, p-issn : 0854-624X

keselamatan dan kesehatan kerja (SMK3) yang ada di dalam organisasi. Sebagaimana tercantum dalam pasal 3 undang-undang nomor 1 tahun 1970 tentang keselamatan kerja telah diatur di dalamnya mengenai kewajiban bagi setiap tempat kerja untuk menerapkan SMK3. Sementara pada pasal 86 Bab X undang-undang no. 13 tahun 2003 tentang Ketenaga kerjaan antara lain menyatakan bahwa setiap pekerja/buruh mempunyai hak untuk memperoleh perlindungan atas K3; untuk melindungi keselamatan pekerja/buruh guna mewujudkan produktivitas kerja yang optimal diselenggarakan upaya K3; dan perlindungan sebagaimana dimaksud dilaksanakan sesuai dengan peraturan perundang-undangan yang berlaku. Penjelasan Pasal 86, ayat (2) menyatakan "upaya K3 dimaksudkan untuk memberikan jaminan keselamatan dan meningkatkan derajat kesehatan para pekerja/buruh dengan cara pencegahan kecelakaan dan penyakit akibat kerja, pengendalian bahaya di tempat kerja, promosi kesehatan, pengobatan, dan rehabilitasi.

Pengetahuan mengenai keselamatan dan kesehatan kerja merupakan hal penting untuk menghindari pekerja dan orang yang berada ditempat pekerjaan tidak mengalami kecelakaan (zero accident) maupun tidak mengalami penyakit akibat kerja (zero PAK). Pengetahuan keselamatan kerja juga berperan dalam pengendalian terhadap sumber peralatan yang mempunyai risiko menjadi sumber bahaya. Keselamatan kerja penting dilaksanakan di jenis pekerjaan formal maupun informal.

$$
\text { Akhir-akhir ini terlihat adanya }
$$

perkembangan yang cukup menggembirakan di bidang K3 di Indonesia. Banyaknya universitas yang menyelenggarakan program studi tentang K3 dan perusahaan yang menerapkan sistem manajemen K3, akan tetapi perkembangan tersebut ternyata masih belum diikuti upaya yang nyata dalam penerapannya di lapangan. Hal tersebut dikarenakan sampai sekarang masih terdapat sejumlah masalah inti dalam K3 yang memerlukan penanganan serius agar program K3 tidak berjalan di tempat dan potensi K3 tidak dapat diberdayakan dengan optimal. Pembenahan yang perlu dilakukan antara lain meliputi pembaruan (amandemen) Undangundang Nomor 1 tahun 1970 terhadap pasalpasal yang dinilai sudah tidak relevan lagi, serta pembuatan skala prioritas terhadap pelaksanaan program K3 dan pemberdayaan potensi K3 di lapangan.

Berdasarkan data dari BPJS Ketenagakerjaan jumlah kasus kecelakaan kerja di Indonesia terus menurun. Tahun 2015 terjadi kecelakaan kerja sebanyak 110.285 kasus, sedangkan tahun 2016 sejumlah 105.182 kasus, sehingga mengalami penurunan sebanyak $4,6 \%$. Sedangkan sampai Bulan Agustus tahun 2017 terdapat sebanyak 80.392 kasus.

Menurut Hanif Dhakiri (Kemkominfo, 2018) "Salah satu penyebab kecelakaan kerja tersebut adalah belum optimalnya pengawasan dan pelaksanaan K3 serta perilaku K3 di tempat kerja. Karena itu, perlu dilakukan upaya yang nyata untuk mencegah dan mengurangi terjadinya kecelakaan maupun penyakit akibat kerja secara maksimal".

Penelitian yang dilakukan sebelumnya oleh Hasbi Ibrahim et al. (2016) menunjukkan bahwa gambaran faktor risiko kecelakaan kerja pada departemen produksi bahan baku di PT.Semen Tonasa Kabupaten Pangkep menyimpulkan bahwa: (1) Dari 146 responden yang diteliti, untuk variabel umur maka responden yang berumur muda (<30 Tahun) lebih banyak mengalami kejadian kecelakaan kerja yaitu 35,6\%. (2) Dari 146 responden yang diteliti, untuk variabel masa kerja maka responden yang memiliki masa kerja lama (>3 Tahun) lebih banyak mengalami kejadian kecelakaan kerja yaitu 46,6\%. (3) Dari 146 responden yang diteliti, untuk variabel lama kerja maka responden yang (Ibrahim, 2016) bekerja selama 14 jam yang mengalami kecelakaan kerja yaitu 60,3\%. (4) Dari 146 responden yang diteliti, untuk variabel penggunaan APD maka responden yang menggunakan alat pelindung diri lebih banyak mengalami kecelakaan kerja yaitu $32,9 \%$. (5) Dari 146 responden yang diteliti, untuk variabel shift kerja maka yang mengalami kecelakaan kerja yaitu 30,1\%. (6) Dari 146 responden yang diteliti, shift 1 yang menggunakan APD yaitu $32,2 \%$ dan yang tidak menggunakan APD yaitu 17,8. Sedangkan shift 2 yang menggunakan APD yaitu $24,7 \%$ dan yang tidak menggunakan APD yaitu $25,3 \%$.

PT. Andalan Fluid Sistem di Kecamatan Mandai Kabupaten Maros adalah perusahaan teknik yang mengkhususkan diri dalam silinder hidrolik dan pneumatik yang menyediakan solusi satu atap dalam meningkatkan efisiensi alat berat. 
Jurnal Sulolipu : Media Komunikasi Sivitas Akademika dan Masyarakat

Vol. 19 No.2 2019

e-issn : 2622-6960, p-issn : 0854-624X

Data yang diperoleh dari PT. Andalan Fluid Sistem bahwa industri ini telah menerapkan Standar Operasional Prosedur (SOP) dengan demikian perusahaan telah memperhatikan masalah keselamatan kerja namun masih ada karyawan yang mengalami insiden, dikarenakan masih ada beberapa kemungkinan faktor penyebab terjadinya kecelakaan kerja seperti: 1) masa kerja karyawan yang dilihat dari kurun waktu atau lamanya karyawan bekerja yang memiliki pengalaman kerja yang berbeda, dimana dapat mempengaruhi kinerja baik positif maupun negatif. 2) Penggunaan APD yang dilihat dari sikap dan tindakan karyawan yang menggunakan alat pelindung diri pada saat bekerja, karena karyawan di PT. Andalan Fluid Sistem masih saja seringkali lalai dalam menggunakan APD pada saat bekerja. 3) Perilaku yang dilihat dari pengetahuan karyawan tentang pentingnya keselamatan dan kesehatan kerja karena dapat mempengaruhi tingkat kecelakaan kerja. 4) Suhu udara berkaitan dengan kondisi lingkungan kerja yang dilihat dari hasil pengukuran dengan alat HygroThermometer dimana suhu dingin dan suhu panas yang berlebihan dapat mengurangi efisiensi karyawan dalam bekerja.

Semenjak perusahaan ini berdiri dari tahun 2016 hingga tahun 2018 ada 16 kasus yang terjadi. Pada tahun 2016 kecelakaan kerja terjadi 8 kasus kecelakaan kerja. Kecelakaan berupa near miss injury, first aid injury, LTI (Lost Time Injury), traffic injury dan MTI (Medical Treatment Injury). Pada tahun 2017 terjadi 5 kasus kecelakaan kerja dan pada tahun 2018 terjadi 3 kasus kecelakaan kerja.

Berdasarkan studi pendahuluan tersebut maka peneliti tertarik mengangkat masalah diatas untuk dijadikan tema penelitian "Faktor yang Memengaruhi Terjadinya Kecelakaan Kerja pada Karyawan di PT. Andalan Fluid Sistem Kabupaten Maros".

\section{METODE}

Penelitian ini dilakukan di PT. Andalan Fluid Sistem Kabupaten Maros.

Tahap persiapan meliputi observasi, menyusun proposal yang berlangsung pada bulan Desember 2018 sampai Januari 2019. Tahap pelaksanaan meliputi kegiatan yang berlangsung pada bulan April 2019.
Jumlah dan cara pengambilan subjek (untuk penelitian survei) atau bahan dan alat (untuk penelitian laboratorium)

Sampel dalam penelitian ini dengan jumlah 65 yang diambil secara total sampling, dimana semua populasi diambil sebagai sampel.

\section{Jenis dan Cara Pengumpulan Data (untuk penelitian survei)/Langkah-Langkah Penelitian (untuk penelitian laboratorium)}

1. Data Primer

Sumber data yang diperoleh langsung dari perusahaan yang menjadi objek penelitian. Data ini mengenai faktor-faktor yang memengaruhi terjadinya kecelakaan kerja terhadap keselamatan kerja dan kesehatan kerja dengan menyebarkan angket kepada karyawan di PT. Andalan Fluid Sistem Kabupaten Maros.

\section{Data Sekunder}

Sumber data tambahan yaitu sumber data yang diperoleh dari sumber lain dengan cara melakukan observasi, wawancara dan pengukuran suhu di lima titik proses tempat bekerja karyawan meliputi; area kerja welding, area kerja chrome dan polishing, building I (gedung I), building II (gedung II), dan area kerja utility. Dimana alat yang digunakan dalam mengukur yaitu Hygrometer.

Prosedur dalam menggunakan alat yaitu :

a. Memegang hygrometer dalam ruangan yang akan diukur suhunya.

b. Setiap 5 menit, catat angka yang tertera.

\section{Pengolahan dan analisis data}

Data dianalisis dengan statistik deskriptif dan statistik inferensial, dengan dibantu program SPSS 2_2 (Statistical product and service solutions) (Hidayat,2015). Dalam analisis data digunakan dua cara yaitu analisis univariat dan bivariat.

\section{Analisis Univariat}

Analisis univariat adalah suatu teknik analisis data terhadap satu variabel secara mandiri, tiap variabel dianalisis tanpa dikaitkan dengan variabel lainnya. Analisis univariat merupakan metode analisis yang paling mendasar terhadap suatu data. Model analisis univariat dapat berupa menampilkan angka hasil 
pengukuran, ukuran tendensi sentral, ukuran dispersi/deviasi/variability, penyajian data ataupun kemiringan data.

Angka hasil pengukuran dapat ditampilkan dalam bentuk angka, atau sudah diolah menjadi persentase, ratio, prevalensi Ukuran tendensi sentral meliputi perhitungan mean, median, kuartil, desil persentil, modus. Ukuran disperse meliputi hitungan rentang, deviasi rat-rata, variansi, standar deviasi, koefisien of variansi. Penyajian data dapat dalam bentuk narasi, tabel, grafik, diagram, maupun gambar. Kemiringan suatu data erat kaitannya dengan model kurva yang dibentuk data.

Analisis univariat bertujuan untuk mendeskripsikan karakteristik masing-masing variabel yang telah diteliti, baik variabel independen maupun dependen.

\section{Analisis Bivariat}

Analisis bivariat menggunakan tabel silang untuk menyoroti dan manganalisis perbedaan atau hubungan antara dua variabel. Menguji ada tidaknya perbedaan/hubungan atara variabel digunakan analisis regresi logistik dengan uji chi square, dengan tingkat kemaknaan à = 0, 05 .

Hasil yang diperoleh pada analisis chi square dengan menggunakan program SPSS yaitu nilai $p$, kemudian dibandingkan dengan à $=0,05$. Apabila nilai $p$ lebih kecil dari à $=0,05$ maka ada hubungan/pengaruh antara dua variabel tersebut. (Santoso, 2000).

Data yang telah diperoleh dari hasil wawancara dan observasi langsung di Lapangan, kemudian di sajikan dalam bentuk tabel dan narasi.

\section{HASIL}

\section{Pengaruh Masa Kerja dengan kejadian kecelakaan kerja}

a. Nilai chi square sebesar 0,133 dengan df 1 , kemudian diperoleh nilai sig.Model sebesar 0,716 karena nilai ini lebih besar dari $5 \%$ atau $0,05 \%$ maka dapat disimpulkan bahwa karyawan yang masa kerjanya $>3$ dan $<3$ tahun tahun tidak memiliki pengaruh secara simultan terhadap kejadian kecelakaan kerja.

b. Nilai Nagelkerke $R$ square sebesar 0,003 dan Cox \& Snell R square 0,002 yang menunjukkan bahwa kemampuan masa kerja dalam menjelaskan variabel kecelakaan kerja adalah sebesar $0,003 \%$ atau $0,3 \%$ dan terdapat $99,7 \%$ faktor lain.

c. Jumlah sampel yang tidak pernah mengalami kecelakaan kerja ada 49 orang dan yang pernah mengalami kecelakaan kerja 16 orang. Tabel di atas memberikan nilai overall percentage sebesar $75,4 \%$, yang berarti ketepatan model penelitian ini sebesar $75,4 \%$.

d. Variabel masa kerja mempunyai nilai sig wald $0,716>0,05$ sehingga menerima Ho. Besarnya pengaruh yang ditunjukkan dengan nilai $\operatorname{Exp}(B)$ 1,234 maka masa kerja $\geq 3$ tahun hanya memiliki resiko 1,234 kali dibandingkan yang memiliki masa kerja $\leq 3$ tahun. Nilai $\mathrm{B}=$ logaritma natural dari 1,234= 0,210 , oleh karena bernilai positif, maka riwayat karyawan yang memiliki pengaruh positif dengan kejadian kecelakaan kerja.

2. Pengaruh penggunaan APD dengan kejadian kecelakaan kerja

a. Nilai chi square sebesar 8,035 dengan df 1 , kemudian diperoleh nilai sig.Model sebesar 0,005 karena nilai ini lebih kecil dari $5 \%$ atau 0,05\% maka dapat disimpulkan bahwa karyawan yang menggunakan APD memiliki pengaruh secara simultan terhadap kejadian kecelakaan kerja.

b. Nilai Nagelkerke $R$ square sebesar 0,173 dan Cox \& Snell $R$ square 0,116 yang menunjukkan bahwa penggunaan APD dalam menjelaskan variabel kecelakaan kerja adalah sebesar $0,173 \%$ atau $17,3 \%$ dan terdapat $82,7 \%$ faktor lain.

c. Jumlah responden yang tidak mengalami kecelakaan kerja 49 responden. Yang benar-benar tidak mengalami kecelakaan kerja 
sebanyak 40 responden dan yang seharusnya tidak mengalami kecelakaan kerja namun mengalami, sebanyak 9 orang. Jumlah responden yang mengalami kecelakaan kerja 16 responden. Yang benar-benar mengalami kecelakaan kerja 7 responden dan yang seharusnya mengalami kecelakaan kerja namun tidak mengalami, sebanyak 9 responden. Dalam Interprestasi regresi logistik dengan SPSS: Tabel di atas memberikan nilai overall percentage sebesar $75,4 \%$ yang berarti ketepatan model penelitian ini adalah sebesar $75,4 \%$.

d. Variabel independen nilai $P$ value $u j i$ wald $(\mathrm{Sig})<0,05$, artinya variabel APD mempunyai pengaruh parsial yang signifikan terhadap kejadian kecelakaan kerja di dalam model. Penggunaan APD mempunyai nilai Sig Wald 0,005 $<0,05$ sehingga menolak $\mathrm{Ho}$ atau yang berarti penggunaan APD memberikan pengaruh parsial yang signifikan terhadap kejadian kecelakaan kerja. Besarnya pengaruh ditunjukkan dengan nilai EXP (B) atau disebut juga ODDS RATIO (OR). Variabel penggunaan APD dengan OR 5,714 maka orang yang tidak menggunakan APD lebih beresiko mengalami kecelakaan kerja sebanyak 5,714 kali lipat di bandingkan orang yang menggunakan. Nilai $B=$ Logaritma Natural dari $5,714=1,743$. Oleh karena nilai $B$ bernilai positif, maka penggunaan APD mempunyai hubungan positif dengan kejadian kecelakaan kerja.

3. Pengaruh perilaku dengan kejadian kecelakaan kerja

a. Nilai chi square sebesar 7,028 dengan df 1 , kemudian diperoleh nilai sig.Model sebesar 0,008 karena nilai ini lebih kecil dari 5\% atau $0,05 \%$ maka dapat disimpulkan bahwa perilaku karyawan memiliki pengaruh secara simultan terhadap kejadian kecelakaan kerja

b. Nilai Nagelkerke $R$ square sebesar 0,152 dan Cox \& Snell R square 0,102 yang menunjukkan bahwa perilaku dalam menjelaskan variabel kecelakaan kerja adalah sebesar $0,152 \%$ atau $15,2 \%$ dan terdapat $84,8 \%$ faktor lain.

c. Jumlah responden yang tidak mengalami kecelakaan kerja 49 responden. Yang benar-benar tidak mengalami kecelakaan kerja sebanyak 40 responden dan yang seharusnya tidak mengalami kecelakaan kerja namun mengalami, sebanyak 9 orang. Jumlah responden yang mengalami kecelakaan kerja 16 responden. Yang benar-benar mengalami kecelakaan kerja 7 responden dan yang seharusnya mengalami kecelakaan kerja namun tidak mengalami, sebanyak 9 responden. Dalam Interprestasi regresi logistik dengan SPSS: Tabel di atas memberikan nilai overall percentage sebesar $75,4 \%$ yang berarti ketepatan model penelitian ini adalah sebesar $75,4 \%$.

d. Variabel independen nilai $P$ value uji wald (Sig) < 0,05, artinya variabel Perilaku mempunyai pengaruh parsial yang signifikan terhadap kejadian kecelakaan kerja di dalam model. Perilaku mempunyai nilai Sig Wald 0,009 < 0,05 sehingga menolak $\mathrm{Ho}$ atau yang berarti perilaku memberikan pengaruh parsial yang signifikan terhadap kejadian kecelakaan kerja. Besarnya pengaruh ditunjukkan dengan nilai EXP (B) atau disebut juga ODDS RATIO (OR). Variabel perilaku dengan OR 5,014 maka orang yang berperilaku kurang lebih beresiko mengalami kecelakaan kerja sebanyak 5,014 kali lipat di bandingkan orang yang 
Jurnal Sulolipu : Media Komunikasi Sivitas Akademika dan Masyarakat

Vol. 19 No.2 2019

e-issn : 2622-6960, p-issn : 0854-624X

menggunakan. Nilai $B=$ Logaritma Natural dari $5,014=1,612$. Oleh karena nilai $B$ bernilai positif, maka perilaku mempunyai hubungan positif dengan kejadian kecelakaan kerja.

4. suhu udara di lingkungan kerja PT. Andalan Fluid Sistem Kab. Maros yang telah diukur dari lima titik memiliki rata-rata suhu $31,32{ }^{\circ} \mathrm{C}$, dimana tidak memenuhi standar Permenkes No 70 Tahun 2016.

\section{PEMBAHASAN}

1. Masa Kerja dengan kejadian kecelakaan kerja

Berdasarkan data yang diperoleh dari hasil penelitian di PT. Andalan Fluid Sistem Kab. Maros menunjukkan bahwa dari 65 responden yang bekerja di PT. Andalan Fluid Sistem Kabupaten Maros, distribusi responden yang paling banyak adalah yang masa kerjanya baru ( $\leq 3$ tahun) sebanyak 34 orang responden $(52,3 \%)$ daripada responden yang masa kerjanya lama ( $>3$ tahun) yaitu 31 responden $(47,7$ $\%)$. Masa kerja lama ( $>3$ tahun) ada sebanyak 31 responden, yang tidak pernah mengalami kecelakaan kerja sebanyak 24 responden $(77,4 \%)$ dan 7 responden $(22,6 \%)$ pernah mengalami kecelakaan kerja. Dan dari 65 responden yang masa kerja baru ( $\leq 3$ tahun) ada sebanyak 34 responden, sebanyak 25 responden $(73,5 \%)$ yang tidak pernah mengalami kecelakaan kerja dan sebanyak 9 responden $(26,5 \%)$ yang pernah mengalami kecelakaan kerja.

Penelitian ini tidak sejalan dengan penelitian Hasbi Ibrahim et al. (2016) gambaran faktor risiko kecelakaan kerja pada departemen produksi bahan baku di PT.Semen Tonasa Kabupaten Pangkep menunjukkan hasil bahwa masa kerja yang banyak adalah masa kerja baru (<3 Tahun) ada sebanyak 20 $(13,7 \%)$ yang pernah mengalami kecelakaan kerja dan ada sebanyak 10 $(6,8 \%)$ yang tidak pernah mengalami kecelakaan kerja. Dan responden yang masa kerjanya lama ( $>3$ Tahun) ada sebanyak 68 (46,6\%) yang pernah mengalami kecelakaan kerja dan ada sebanyak 48 (32,9\%) yang tidak pernah mengalami kecelakaan kerja.

Masa kerja adalah suatu kurun waktu atau lamanya tenaga kerja bekerja disuatu tempat. Masa kerja dapat mempengaruhi kinerja baik positif maupun negatif. Memberi pengaruh positif pada kinerja bila dengan semakin lamanya masa kerja seseorang semakin berpengalaman dalam melaksanakan tugasnya. Sebaliknya, akan memberi pengaruh negatif apabila dengan semakin lamanya masa kerja akan timbul kebiasaan pada tenaga kerja. Dengan masa kerja yang bertambah maka pengetahuan dan keterampilan seseorang tenaga kerja juga bertambah dan aspek keselamatan diri dari pekerjaannya yang dilakukan sehingga dapat terhindar dari segala risiko terjadinya kecelakaan kerja.

Berdasarkan hasil perbandingan penelitian tersebut, variabel masa kerja mempunyai nilai sig wald 0,716 >0,05 sehingga menerima Ho. Besarnya pengaruh yang ditunjukkan dengan nilai $\operatorname{Exp(B)~1,234~maka~masa~kerja~} \geq 3$ tahun hanya memiliki resiko 1,234 kali dibandingkan yang memiliki masa kerja $\leq 3$ tahun. Nilai $\mathrm{B}=$ logaritma natural dari $1,234=0,210$, oleh karena bernilai positif, maka riwayat karyawan yang memiliki pengaruh postif dengan kejadian kecelakaan kerja.

2. Penggunaan APD dengan kejadian kecelakaan kerja

Berdasarkan hasil pengolahan data menunjukkan bahwa dari 65 responden yang bekerja di PT. Andalan Fluid Sistem Kabupaten Maros, yang menggunakan APD dengan lengkap sebanyak 47 responden, yang mengalami kecelakaan kerja sebanyak 7 responden (14,9\%) dan yang tidak mengalami kecelakaan kerja sebanyak 40 responden $(85,1 \%)$, yang tidak menggunakan APD dengan lengkap 
Jurnal Sulolipu : Media Komunikasi Sivitas Akademika dan Masyarakat

Vol. 19 No.2 2019

e-issn : 2622-6960, p-issn : 0854-624X

yaitu 18 responden, yang mengalami kecelakaan kerja sebanyak 9 responden $(50,0 \%)$ dan yang tidak mengalami kecelakaan kerja 9 responden (50,0 \%). Hasil persentasenya menunjukkan bahwa responden yang tidak menggunakan APD dengan lengkap saat bekerja cenderung mengalami kecelakaan kerja dibandingkan dengan responden yang menggunakan APD lengkap saat bekerja sesuai dengan Permenakertrans No. 8 tahun 2010. Penelitian ini sejalan dengan penelitian yang telah dilakukan oleh Sulhinayatillah di PT. LONSUM Indonesia Tbk, Kab. Bulukumba tahun 2017, dimana didapatkan hasil persentase risiko kecelakaan kerja yang lebih tinggi terjadi pada tenaga kerja yang tidak menggunakan APD pada saat bekerja yaitu dari 54 responden ada 47 responden $(54,7 \%)$ yang pernah mengalami kecelakaan kerja yang tidak mnggunakan APD lengkap dan dari 32 responden yang lengkap menggunakan APD pada saat bekerja ada sebanyak 11 responden (12,8\%) yang pernah mengalami kecelakaan kerja. Hal ini menunjukkan adanya pengaruh yang signifikan antara penggunaan APD dengan kecelakaan kerja yang terajdi di tempat kerja.

Dari hasil observasi yang dilakukan bahwa tingginya angka kecelakaan kerja, diakibatkan oleh karyawan yang tidak menjalankan aturan yang telah diperintahkan sebelumnya, penggunaan APD yang diwajibkan oleh perusahaan pada saat melakukan pekerjaan agar karyawan terhindar dari risiko kecelakaan kerja. Karena dengan menggunakan APD dengan baik dan tepat sesuai dengan fungsinya pada tenaga kerja dalam melakukan pekerjaan sangat penting dalam usaha pencegahan kecelakaan dan penyakit akibat kerja serta perlindungan tenaga kerja.

Berdasarkan hasil uji regresi logistik, variabel independen nilai $P$ value uji wald $(\mathrm{Sig})<0,05$, artinya variabel APD mempunyai pengaruh parsial yang signifikan terhadap kejadian kecelakaan kerja di dalam model. Penggunaan APD mempunyai nilai Sig Wald 0,005 < 0,05 sehingga menolak Ho atau yang berarti penggunaan APD memberikan pengaruh parsial yang signifikan terhadap kejadian kecelakaan kerja.

Besarnya pengaruh ditunjukkan dengan nilai EXP (B) atau disebut juga ODDS RATIO (OR). Variabel penggunaan APD dengan OR 5,714 maka orang yang tidak menggunakan APD lebih beresiko mengalami kecelakaan kerja sebanyak 5,714 kali lipat di bandingkan orang yang menggunakan. Nilai $B=$ Logaritma Natural dari $5,714=1,743$. Oleh karena nilai B bernilai positif, maka penggunaan APD mempunyai hubungan positif dengan kejadian kecelakaan kerja.

3. Perilaku dengan kejadian kecelakaan kerja

Berdasarkan data yang
diperoleh dari hasil penelitian menunjukkan bahwa dari 65 responden yang bekerja di PT. Andalan Fluid Sistem Kabupaten Maros, yang memberi respon baik ada sebanyak 46 responden, yang tidak pernah mengalami kecelakaan kerja sebanyak 39 responden $(84,4 \%)$ dan 7 responden $(15,2 \%)$ pernah mengalami kecelakaan kerja. Dan dari 65 responden yang memberi respon kurang sebanyak 19 responden, ada sebanyak 10 responden $(52,6 \%)$ yang tidak pernah mengalami kecelakaan kerja dan sebanyak 9 responden $(47,4 \%)$ yang pernah mengalami kecelakaan kerja.

Penelitian ini sejalan dengan penelitian yang telah dilakukan oleh Sulhinayatillah di PT. LONSUM Indonesia Tbk, Kab. Bulukumba tahun 2017, dimana diketahui bahwa dari 25 responden yang berperilaku baik, ada sebanyak 11 responden (12,8\%) yang pernah mengalami kecelakaan kerja dan 14 responden $(16,3 \%)$ yang tidak pernah mengalami kecelakaan kerja. Dan dari 61 responden yang berperilaku buruk, ada sebanyak 47 
responden (54,7 \%) yang pernah mengalami kecelakaan kerja dan 14 responden $((16,3 \%)$ yang tidak pernah mengalami kecelakaan kerja. Hasil persentasenya menunjukkan bahwa perilaku dan pengetahuan karyawan yang kurang lebih cenderung mengalami kecelakaan kerja dibanding dengan perilaku dan pengetahuan yang baik. Oleh karena itu, karyawan yang berperilaku dan memiliki pengetahuan yang kurang dapat menyebabkan kecelakaan dikarenakan kelalaian disaat bekerja. Pengetahuan yang kurang disni dapat dilihat dari tingkat pendidikan yang berbeda-beda dari karyawan yang bekerja di PT. Andalan Fluid Sistem Kab. Maros.

Berdasarkan hasil uji regresi logistik, variabel independen nilai $P$ value uji wald $(\mathrm{Sig})<0,05$, artinya variabel Perilaku mempunyai pengaruh parsial yang signifikan terhadap kejadian kecelakaan kerja di dalam model. Perilaku mempunyai nilai Sig Wald $0,009<0,05$ sehingga menolak Ho atau yang berarti perilaku memberikan pengaruh parsial yang signifikan terhadap kejadian kecelakaan kerja.

Besarnya pengaruh ditunjukkan dengan nilai EXP (B) atau disebut juga ODDS RATIO (OR). Variabel perilaku dengan OR 5,014 maka orang yang berperilaku kurang lebih beresiko mengalami kecelakaan kerja sebanyak 5,014 kali lipat di bandingkan orang yang menggunakan. Nilai $B=$ Logaritma Natural dari 5,014= 1,612. Oleh karena nilai B bernilai positif, maka perilaku mempunyai hubungan positif dengan kejadian kecelakaan kerja.

4. Suhu Udara lingkungan kerja dengan kejadian kecelakaan kerja

Berdasarkan hasil pengukuran suhu udara di lingkungan kerja PT. Andalan Fluid Sistem Kab. Maros diperoleh hasil yang telah diukur dari lima titik memiliki rata-rata suhu 31,32 ${ }^{0} \mathrm{C}(20 \%)$, dimana suhu tersebut tidak memenuhi standar Permenkes No. 70 Tahun 2016, karena dapat dikatakan memenuhi standar apabila suhu $18^{\circ} \mathrm{C}-$ $30^{\circ} \mathrm{C}$, dan apabila suhu diatas $30^{\circ} \mathrm{C}$ maka tidak memenuhi standar. Namun hasil pengukuran suhu udara lingkungan kerja tidak dapat diuji karena nilainya konstan berada di atas nilai ambang batas suhu lingkungan kerja industri dan dapat dikatakan bahwa ada pengaruh suhu udara dengan kejadian kecelakaan kerja.

Ketika suhu ruangan yang tinggi maka suhu tubuh juga akan meningkat karena terjadi penyerapan panas oleh kulit sehingga pembuluh darah yang ada di permukaan kulit (pembuluh darah perifer) akan melebar akibatnya terjadi perpindahan panas ke dalam tubuh maka akan menjadi panas dengan cara radiasi dan konduksi.

Pengeluaran keringat berlebihan akan menyebabkan tubuh kekurangan cairan dan dapat menurunkan kandungan ion natrium dan klorida karena keringat mengandung bermacam-macam zat elektrolit (terutama natrium dan klorida) yang akan ikut keluar bersama keringat, sehingga menyebabkan keseimbangan cairan akan terganggu. Kehilangan elektrolit juga akan mengganggu pasokan darah ke organ tubuh dan pada akhirnya akan menyebabkan kelelahan yang dimana dapat memicu terjadinya kecelakaan kerja.

\section{KESIMPULAN}

Dari hasil penelitian yang telah dilakukan di PT. Andalan Fluid Sistem Kab. Maros dapat disimpulkan bahwa :

1. Tidak ada pengaruh signifikan secara simultan masa kerja dengan kejadian kecelakaan kerja pada karyawan PT.Andalan Fluid Sistem Kab.Maros oleh karena nilai $p$ value Chi-Square sebesar 0,716 di mana > Alpha 0,05 atau nilai ChiSquare Hitung $0,133<$ Chi-Square tabel 3,84 .

2. Ada pengaruh signifikan secara simultan penggunaan APD dengan kejadian kecelakaan kerja pada karyawan PT.Andalan Fluid Sistem Kab.Maros oleh 
Jurnal Sulolipu : Media Komunikasi Sivitas Akademika dan Masyarakat

Vol. 19 No.2 2019

e-issn : 2622-6960, p-issn : 0854-624X

karena nilai $p$ value Chi-Square sebesar 0,005 di mana $<$ Alpha 0,05 atau nilai ChiSquare Hitung 8,035 > Chi-Square tabel 3,84.

3. Ada pengaruh signifikan secara simultan perilaku dengan kejadian kecelakaan kerja pada karyawan PT.Andalan Fluid Sistem Kab.Maros oleh karena nilai $p$ value ChiSquare sebesar 0,008 di mana < Alpha 0,05 atau nilai Chi-Square Hitung 7,028 > Chi-Square tabel 3,84.

4. Ada pengaruh antara suhu udara dengan kejadian kecelakaan kerja pada karyawan di PT. Andalan Fluid Sistem Kabupaten Maros oleh karena diperoleh hasil yang telah diukur dari lima titik memiliki rata-rata suhu $31,32{ }^{\circ} \mathrm{C}$, dimana suhu tersebut tidak memenuhi standar Permenkes No. 70 Tahun 2016

\section{SARAN}

1. Kepada perusahaan untuk lebih meningkatkan pentingnya pengawasan mengenai kedisiplinan penggunaan alat pelindung diri (APD) kepada tenaga kerja.

2. Kepada karyawan untuk lebih memperhatikan pengetahuan mengenai sistem manajemen keselamatan dan kesehatan kerja sesuai SOP yang berlaku di perusahaan.

3. Kepada SHE perusahaan untuk melakukan pengukuruan suhu udara lingkungan kerja secara berkala agar karyawan nyaman dalam bekerja.

\section{DAFTAR PUSTAKA}

Ansari. L. H.. dan Azkha. N.. 2017. Faktor-faktor yang Berhubungan dengan Kecelakaan Kerja pada Karyawan PT Kunanggo Jantan Kota Padang Tahun 2016. (Online) http://eprints.uad.ac.id/5417/ Diakses 14 Desember 2018

Buntarto. 2015. Panduan Praktis Keselamatan \& Kesehatan Kerja untuk Industri. Yogyakarta: Pustaka Baru

Press.

Daryanto, S. \&. 2018. Pedoman Praktis K3LH. Yogyakarta: Gava Media.

Osha. 2018. 3 Faktor Penyebab Kecelakaan Kerja (Three Main Factor Theory). (Online) https://www.safetyshoe.com/3-faktor-penyebab kecelakaan-kerja-k3-mencakup-5-m-faktor-manusial. Desember 2018.

Wowo Sunaro Kuswana, M. 2017. Ergonomi dan K3. Bandung: PT. Remaja Rosdakarya.

Hidayat, A Aziz Alimul. 2017. Metode Penelitian Keperawatan Dan Kesehatan. Jakarta: Salemba Medika.

Ibrahim. Hasbi.. Amansyah. Munawir. Amalia. Nur W. T. 2016. Gambaran Faktor Risiko Kecelakaan Kerja Pada Departemen Produksi Bahan Baku Di PT. Semen Tonasa Kabupaten Pangkep. Skripsi. $\quad$ http://journal.uin-alauddin.ac.id/index.php/Al-Sihah/article/view/3145 Diakses 13 Desember 2018

ILO/WHO, C. J. (1995). oint ILO/WHO Committee on Occupational. ILO. (online) https://www.ilo.org/wcmsp5/groups/public/@dgreports/@dcomm/@publ/documents/publication/w cms_093550.pdf. Diakses 14 Desember 2018

Isriyadi. Budi. 2015. Hubungan Masa Kerja Dengan Tingkat Kecemasan Perawat Di Ruang Akut Rumah Sakit Jiwa Daerah Surakarta. Skripsi. Jurusan Keperawatan Stikes Kusuma Husada. Surakarta. (online)http://digilib.stikeskusumahusada.ac.id/download.php?id=1264 Diakeses 13 Desember 2018 
Jurnal Sulolipu : Media Komunikasi Sivitas Akademika dan Masyarakat

Vol. 19 No.2 2019

e-issn : 2622-6960, p-issn : 0854-624X

Kemkominfo, B. H. 2018. Menaker Hanif Canangkan Peringatan Bulan K3 Nasional 2018. Jakarta: Biro Humas Kemnaker bersama Tim Komunikasi Pemerintah Kemkominfo. (Online) http://www.depkes.go.id/article/view/18012200004/menaker-hanif-canangkan-peringatan-bulank3-nasional-2018.html Di Akses 14 Desember 2018

Notoatmodjo. Soekidjo. 2012. Metodologi Penelitian Kesehatan. Jakarta: Rineka Cipta.

OHSAS. (2007). Occupational Health and Safety Management System-Requirement. (online) https://nuruddinmh.files.wordpress.com/2013/08/ohsas-18001-2007-dual-language.pdf Diakses 14

Desember

2018

Ramli, S. (2010). Pedoman Praktis Manajemen Risiko dalam Perseptif K3. Jakarta: Dian Rakyat.

Rejeki, S. (2015). Sanitasi Hygiene dan Kesehatan \& Keselamatan Kerja (K3). Bandung: Rekayasa Sains.

Republik Indonesia. 1992. Undang-undang Republik Indonesia No.3 tahun 1992 tentang Jaminan Sosial Tenaga Kerja

Republik Indonesia. 1970. Undang-undang Republik Indonesia No.1 tahun 1970 tentang keselamatan kerja.

Republik Indonesia. 2010. Peraturan Menteri Tenaga Kerja dan Transmigrasi Republik Indonesia No PER.08/MEN/VII/2010 Tentang Alat Pelindung Diri.

Republik Indonesia. 2003. Undang- undang Republik Indonesia No.13 tahun 2003 tentang ketenagakerjaan.

Republik Indonesia Nomor 50 Tahun 2012 Tentang Penerapan Sistem Manajemen Keselamatan Dan Kesehatan Kerja.

Republik Indonesia. 2016. Peraturan Menteri Kesehatan Republik Indonesia Nomor 70 Tahun 2016 Tentang Standar Dan Persyaratan Kesehatan Lingkungan Kerja Industri.

Riyanto, Agus. 2017. Aplikasi Metodologi Penelitian Kesehatan. Yogyakarta:Nuha Medika.

Sabri, Luknis. dan Priyo Hastono. Sutanto. 2018. Statistik Kesehatan.

Depok: PT. Raja Grafindo Persada.

Santoso, Singgih, 2000, Spss Version 7.5 [Computer Systems], Jakarta: PT. Elex Media Komputindo Kelompok Gramedia, Jakarta.

Sulhinayatillah. 2017. Faktor-Faktor Yang Berhubungan Dengan Kejadian Kecelakaan Kerja PadaKaryawan Bagian Produksi di PT. PP London Sumatra Indonesia Tbk,Palangisang Crumb Rubber Factory, BulukumbaSulawesi Selatan. Jurusan Kesehatan Masyarakat UIN Alauddin Makassar. (online) http://repositori.uin-alauddin.ac.id/8104/1/Sulhinayatillah.pdf Di Akses 14 Desember 2018

Wibowo. Adik. 2014. Metode Penelitian Praktis Bidang Kesehatan. Jakarta: PT. RajaGrafindo Persada. 
Jurnal Sulolipu : Media Komunikasi Sivitas Akademika dan Masyarakat

Vol. 19 No.2 2019

e-issn : 2622-6960, p-issn : 0854-624X

Tabel 1.

Omnibus tests

Omnibus Tests of Model Coefficients

\begin{tabular}{|cc|c|c|c|}
\hline & $\begin{array}{c}\text { Chi-sq } \\
\text { uare }\end{array}$ & Df & Sig. \\
\hline \multirow{3}{*}{ Step 1 } & Step & .133 & 1 & .716 \\
& Block & .133 & 1 & .716 \\
& Model & .133 & 1 & .716 \\
\hline
\end{tabular}

Sumber output spss:2019

Tabel 2.

Koefisien determinasi

Model Summary

\begin{tabular}{|l|r|r|r|}
\hline Step & $\begin{array}{c}-2 \text { Log } \\
\text { likelihood }\end{array}$ & $\begin{array}{c}\text { Cox \& Snell R } \\
\text { Square }\end{array}$ & Nagelkerke R Square \\
\hline 1 & $72.417^{\mathrm{a}}$ & .002 & .003 \\
\hline
\end{tabular}

a.Estimation terminated at iteration number 4 because parameter estimates changed by less than .001 .

Sumber output spss:2019

Tabel 3

Matriks prediksi

\section{Classification Table ${ }^{a}$}

\begin{tabular}{|c|c|c|c|c|}
\hline \multirow[b]{3}{*}{ Observed } & & \multicolumn{3}{|c|}{ Predicted } \\
\hline & & \multicolumn{2}{|c|}{ kecelakaan kerja } & \multirow{2}{*}{$\begin{array}{c}\text { Percentag } \\
\text { e Correct }\end{array}$} \\
\hline & & tidak pernah & pernah & \\
\hline \multirow[t]{2}{*}{ kecelakaan kerja } & tidak pernah & 49 & 0 & 100.0 \\
\hline & Pernah & 16 & 0 & .0 \\
\hline \multicolumn{2}{|l|}{ Overall Percentage } & & & 75.4 \\
\hline
\end{tabular}

a. The cut value is .500

Sumber output spss:2019

Tabel 4

Hasil uji koefisien regresi logistik

Variables in the Equation

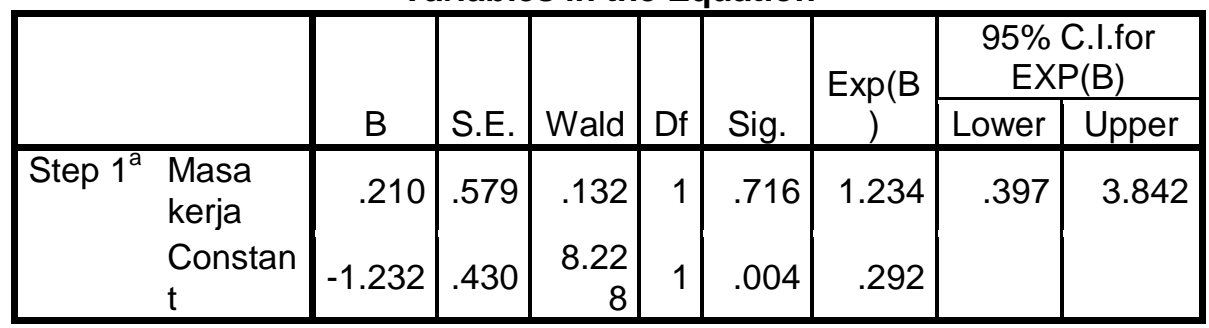

a. Variable(s) entered on step 1: masa kerja.

Sumber output spss:2019 
Jurnal Sulolipu : Media Komunikasi Sivitas Akademika dan Masyarakat

Vol. 19 No.2 2019

e-issn : 2622-6960, p-issn : 0854-624X

Tabel 5

Omnibus Tests

Omnibus Tests of Model Coefficients

\begin{tabular}{|ll|c|c|c|}
\hline & & Chi-square & Df & Sig. \\
\hline Step 1 & Step & 8.035 & 1 & .005 \\
& Block & 8.035 & 1 & .005 \\
& Model & 8.035 & 1 & .005 \\
\hline
\end{tabular}

Sumber output spss:2019

Tabel 6

Koefisien Determinasi

Model Summary

\begin{tabular}{|l|r|r|r|}
\hline Step & $\begin{array}{c}-2 \text { Log } \\
\text { likelihood }\end{array}$ & $\begin{array}{c}\text { Cox \& Snell R } \\
\text { Square }\end{array}$ & Nagelkerke R Square \\
\hline 1 & $64.514^{2}$ & .116 & .173 \\
\hline
\end{tabular}

a. Estimation terminated at iteration number 4 because parameter estimates changed by less than .001 .

Sumber output spss:2019

Tabel 7

Classification Table ${ }^{a}$

\begin{tabular}{|c|c|c|c|c|c|}
\hline & \multirow[b]{3}{*}{ Observed } & & \multicolumn{3}{|c|}{ Predicted } \\
\hline & & & \multicolumn{2}{|c|}{ Kecelakaan Kerja } & \multirow[b]{2}{*}{ Percentage Correct } \\
\hline & & & 0 & 1 & \\
\hline \multirow[t]{3}{*}{ Step 1} & \multirow{2}{*}{$\begin{array}{l}\text { Kecelakaan } \\
\text { Kerja }\end{array}$} & 0 & 40 & 9 & 81.6 \\
\hline & & 1 & 7 & 9 & 56.3 \\
\hline & \multicolumn{2}{|c|}{ Overall Percentage } & & & 75.4 \\
\hline
\end{tabular}

a. The cut value is .500

Sumber output spss:2019

a

Tabel 8

Hasil uji koefisien regresi logistic

Tabel 9

Variables in the Equation

\begin{tabular}{|c|c|c|c|c|c|c|c|c|c|}
\hline & \multirow[b]{2}{*}{$B$} & \multirow[b]{2}{*}{ S.E. } & \multirow[b]{2}{*}{ Wald } & \multirow[b]{2}{*}{ Df } & \multirow[b]{2}{*}{ Sig. } & \multirow[b]{2}{*}{$\operatorname{Exp}(B)$} & \multicolumn{2}{|c|}{$\begin{array}{c}95 \% \text { C.I.for } \\
\operatorname{EXP}(B)\end{array}$} \\
\hline & & & & & & & & Lower & Upper \\
\hline \multirow[t]{2}{*}{ Step $1^{a}$} & APD & 1.743 & .625 & 7.788 & 1 & .005 & 5.714 & 1.680 & 19.435 \\
\hline & Constant & -1.743 & .410 & 18.098 & 1 & .000 & .175 & & \\
\hline
\end{tabular}

a. Variable(s) entered on step 1: APD. 
Jurnal Sulolipu : Media Komunikasi Sivitas Akademika dan Masyarakat

Vol. 19 No.2 2019

e-issn : 2622-6960, p-issn : 0854-624X

\section{Omnibus Tests}

Omnibus Tests of Model Coefficients

\begin{tabular}{|c|c|c|c|c|}
\hline & & Chi-square & Df & Sig. \\
\hline \multirow[t]{3}{*}{ Step 1} & Step & 7.028 & 1 & .008 \\
\hline & Block & 7.028 & 1 & .008 \\
\hline & Model & 7.028 & 1 & .008 \\
\hline
\end{tabular}

Tabel 10

Koefisien Determinasi

Model Summary

\begin{tabular}{|l|r|r|rr|}
\hline Step & -2 Log likelihood & \multicolumn{2}{|c|}{$\begin{array}{c}\text { Cox \& Snell R } \\
\text { Square }\end{array}$} & \multicolumn{2}{|c|}{ Nagelkerke R Square } \\
\hline 1 & $65.521^{\mathrm{a}}$ & .102 & & .152 \\
\hline
\end{tabular}

a. Estimation terminated at iteration number 4 because parameter estimates changed by less than .001 .

Sumber output spss:2019

\section{Tabel 11 \\ Matriks Prediksi}

\begin{tabular}{|c|c|c|c|c|}
\hline \multicolumn{5}{|c|}{ Classification Table $^{\mathrm{d}}$} \\
\hline & & \multicolumn{3}{|c|}{ Predicted } \\
\hline \multirow[b]{2}{*}{ Observed } & & \multicolumn{2}{|c|}{ kecelakaan kerja } & \multirow{2}{*}{$\begin{array}{c}\text { Percentage } \\
\text { Correct }\end{array}$} \\
\hline & & Tidak & ya & \\
\hline \multirow[t]{2}{*}{ kecelakaan kerja } & Tidak & 49 & 0 & 100.0 \\
\hline & $\mathrm{Ya}$ & 16 & 0 & .0 \\
\hline Overall Percentag & & & & 75.4 \\
\hline
\end{tabular}

a. The cut value is .500

Sumber output spss:2019

Tabel 12

Hasil uji koefisien regresi logistic

\begin{tabular}{|c|c|c|c|c|c|c|c|c|c|}
\hline \multicolumn{10}{|c|}{ Variables in the Equation } \\
\hline & & \multirow[b]{2}{*}{ B } & \multirow[b]{2}{*}{ S.E. } & \multirow[b]{2}{*}{ Wald } & \multirow[b]{2}{*}{ df } & \multirow[b]{2}{*}{ Sig. } & \multirow[b]{2}{*}{$\operatorname{Exp}(B)$} & \multicolumn{2}{|c|}{$\begin{array}{c}95 \% \text { C.I.for } \\
\operatorname{EXP}(B)\end{array}$} \\
\hline & & & & & & & & Lower & Upper \\
\hline \multirow[t]{2}{*}{ Step $1^{a}$} & $\mathrm{P}$ & 1.612 & .616 & 6.848 & 1 & .009 & 5.014 & 1.499 & 16.775 \\
\hline & Constant & -1.718 & .410 & 17.510 & 1 & .000 & .179 & & \\
\hline
\end{tabular}

a. Variable(s) entered on step 1: $p$.

Sumber output spss:2019 
Jurnal Sulolipu : Media Komunikasi Sivitas Akademika dan Masyarakat

Vol. 19 No.2 2019

e-issn : 2622-6960, p-issn : 0854-624X

Tabel 13

Hasil Pengukuran Suhu Udara Lingkungan Kerja di PT. Andalan Fluid Sistem Kab. Maros Tahun 2019:

\begin{tabular}{|c|l|c|}
\hline \multirow{2}{*}{ No } & \multicolumn{1}{|c|}{ Titik Pengukuran } & $\begin{array}{c}\text { Hasil Pengukuran } \\
\left({ }^{0} \mathrm{C}\right)\end{array}$ \\
\hline 1 & Building I & $31,5^{\circ} \mathrm{C}$ \\
\hline 2 & Area Kerja Chrome \& Polishing & $30,9^{\circ} \mathrm{C}$ \\
\hline 3 & Area Kerja Welding & $30,8^{\circ} \mathrm{C}$ \\
\hline 4 & Building II & $30,6^{\circ} \mathrm{C}$ \\
\hline 5 & Area Kerja Utility & $32,8^{\circ} \mathrm{C}$ \\
\hline & Jumlah & $156,6^{\circ} \mathbf{C}$ \\
\hline & Rata -rata & $\mathbf{3 1 , 3 2} \mathbf{~}^{\circ} \mathbf{C}$ \\
\hline
\end{tabular}

Sumber : Data Primer, 2019 